Research Article

\title{
Dark Triad traits as predictors of adherence to traditional masculine norms in men
}

\author{
George Van Doorn ${ }^{\boxplus 1,2,3}$ (iD) and Jacob Dye ${ }^{3,4}$ (iD)
}

${ }^{1}$ School of Science, Psychology and Sport, Churchill Campus, Federation University Australia, Churchill, VIC, 3842, Australia

2 Health Innovation and Transformation Centre, Mt Helen Campus, Federation University Australia, Ballarat, VIC, 3350, Australia

${ }^{3}$ Successful Health for At-Risk Populations (SHARP) Research Group, Mt Helen Campus, Federation University Australia, Ballarat, VIC, 3350, Australia

${ }^{4}$ School of Science, Psychology, and Sport, Mt Helen Campus, Federation University Australia, Ballarat, VIC 3350, Australia

\section{ABSTRACT}

The present study examined whether Dark Triad traits explain variance in men's adherence to traditional masculine norms (Playboy, Self-Reliance, Emotional Control, Winning, Violence, Heterosexual Self-Presentation, Risk-Taking, and Power over Women). Two-hundred and thirty-seven English speaking men (aged 18 to 62 years) completed online versions of the Self-Report Psychopathy ScaleIII, the Narcissistic Personality Inventory, the Mach-IV, and the Conformity to Masculine Norms Inventory-29. Results from regression analyses showed that the psychopathic trait Callous Affect positively predicted men's Need to Win, Emotional Control, Violence, and Power Over Women; Erratic Lifestyle was a positive predictor of Risk-Taking; and Antisocial Behaviour was a positive predictor of Playboy. Machiavellianism predicted only Violence. The Narcissistic sub-trait Leadership positively predicted Risk-Taking; Manipulativeness predicted Risk-Taking and Violence; Superiority predicted Risk-Taking and Power over Women; Vanity predicted Self-Reliance; and Exhibitionism predicted Emotional Control. We conclude that whilst Callous Affect appears to hold the highest 
predictive validity, the Dark Triad traits differentially predict adherence to specific masculine norms.

Keywords: masculinity; Dark Triad; psychopathy; Machiavellianism; narcissism

UDC: 159.923.072:159.97

DOI: 10.19090/pp.2021.4. 539-569

Received: 02.09.2021.

Revised: 19.10.2021.

Accepted: 15.11.2021.

Copyright (c) 2021 The Author(s).

This is an open access article distributed under the terms of the Creative Commons Attribution License, which permits unrestricted use, distribution, and reproduction in any medium, provided the original author and source are credited.

$\bowtie$ Corresponding author email: george.vandoorn@federation.edu.au 


\section{Introduction}

Traditional masculine norms represent men's role expectations and behaviour (Gordon et al., 2013). It is recognised that there are multifarious masculinities, and that the prevailing form of masculinity changes across time and geography (Connell, 2005, 2016; Jewkes et al., 2015). Although influenced by women (Connell, 2005), in Western societies masculinity is frequently aligned with the beliefs of heterosexual, well-educated, white men from middle- and upper-class backgrounds (Perkins, 2015). Traditional masculinity is often associated with negative and socially averse behaviours (Connell, 1987; Kupers, 2005). As measured by the Conformity to Masculine Norms Inventory-29 (CMNI-29; Hsu \& Iwamoto, 2014), those who stridently adhere to traditional masculine norms act aggressively (i.e., Violence), lack concern for, marginalise, and dominate others, avoid being perceived of as gay or feminine (i.e., Heterosexual Self-Presentation), display misogynistic attitudes (i.e., Power over Women), are unwilling to accept help (i.e., Self-Reliance), desire multiple sexual partners (i.e., Playboy), display a restricted range of emotions (i.e., Emotional control), and strive to win at any cost (i.e., Winning; Carrigan et al., 1985; Connell, 1987, 2000; Donaldson, 1993; Kahn, 2009; Kupers, 2005; Mankowski \& Maton, 2010; Parent \& Moradi, 2011; Parent et al., 2019; Thacker, 2019).

The Dark Triad (DT) traits are conceptually related, socially aversive dimensions of personality and include subclinical psychopathy, Machiavellianism, and subclinical narcissism (Paulhus \& Williams, 2002). Psychopathy is commonly characterised by a two-factor structure with Factor 1 consisting of deception, manipulation, callousness, and empathy deficits, while Factor 2 consists of antisocial behaviours, impulsivity, poor behavioural control, and an erratic lifestyle (Hare, 2003; Hare \& Neumann, 2008). Williams et al. (2003) further separate these factors into subscales Interpersonal Manipulation, Callous Affect, Erratic Lifestyle, and Antisocial Behaviour - capturing a four-facet model of psychopathy. Machiavellianism is characterised by strategic manipulation, disregard for morality, and 
emotional detachment (Geis \& Levy, 1970; Jones \& Paulhus, 2014). The factor structure of the most used measure of Machiavellianism, Mach-IV (Christie \& Geis, 1970), has been debated (see Monaghan et al., 2018). Christie and Geis (1970) originally suggested a three-factor structure (i.e., Interpersonal Tactics, Cynical View of Human Nature, and Disregard for Conventional Morality). However, later research has shown this structure to be unstable (Monaghan et al., 2018). It is common for contemporary research to utilise a unidimensional Mach-IV structure. Narcissism is characterised by inflated selfworth, entitlement, and pre-occupation with the self (Caligor et al., 2015). The most established measure of non-clinical narcissistic traits is the Narcissistic Personality Inventory and recent research suggests that a five-factor structure is the best fit for this construct (Leadership, Exhibitionism, Vanity, Manipulativeness, and Superiority; Dinić \& Vujić, 2019). Researchers (e.g., Jones \& Figueredo, 2013) suggest that the DT traits share a common core represented by the facets of Hare's (2003) Factor 1 (i.e., interpersonal manipulation and callous affect). Of note to the current study, men on average score higher on each of the DT traits than do women (Jonason et al., 2010). Some research suggests that although most of the dark traits are dimensional in nature, the Dark Core may be a categorical, higher-order trait in men (Tran et al., 2018). This would go some way to explaining the uniformly elevated levels of Dark Core traits in men relative to women.

However, regardless of the shared variance between the DT traits, prior research has established that DT traits distinctively explain variance in other constructs and behaviours. Heym et al. (2019), for example, showed that in a mixed-gender student sample, DT traits are differentially related to outcomes associated with the shared Dark Core, with each of the DT traits having distinct associations with cognitive/affective empathy and indirect relational aggression. Further, Miller et al. (2019) argued that the DT should be treated as multidimensional, and that the unidimensional Dark Core is the result of psychopathy and Machiavellianism being indistinct from one another. For this reason, it would be expected that, although the traits, factors, and facets of the DT may share important features with traditional 
masculinity, examining the differential associations between facets of each of the DT traits (e.g., Callous Affect) with traditional masculine norms (e.g., Violence) may offer important insights.

Although logical connections can be drawn between the DT and traditional masculinity based on intersecting associations, direct relationships have not been established. Given the conceptual overlap between the DT and traditional masculinity, adherence to certain masculine norms may be predicted by high levels of dark traits in men. To the best of our knowledge, only one study has directly assessed the relationship between the DT and masculinity. Jonason and Davis (2018) found, in two mixed-gender student samples, that psychopathy and narcissism were associated with greater adherence to masculine gender roles; although after removing shared variance, only narcissism was associated with adhering to masculine roles. As part of a study investigating emotional manipulation, Waddell et al. (2020) found small-to-moderate bivariate associations between hegemonic masculinity (i.e., the idealised and prevailing form of masculinity; Courtenay, 2000; Perkins, 2015) and DT, with all three DT constructs being positively associated with hegemonic masculinity. Waddell et al. analysed correlations by gender and found that, although these associations held up across genders, the associations between DT traits and adherence to masculine norms were stronger for men than women. Further, men had significantly higher levels of psychopathy and adherence to masculine norms than did women. Although Jonason and Davis (2018) explored the association between DT and masculinity and Waddell et al. (2020) found correlations between the DT and hegemonic masculinity, there is a dearth of research exploring the DT as predictors of adherence to traditional masculine norms.

\section{Psychopathy and masculinity}

Literature shows that psychopathy in males has been associated with hostile and negative attitudes towards women, as well as violence towards and sexual dominance over women (LeBreton et al., 2013; Methot-Jones, 
2019). Individuals with high levels of psychopathy also use coercive tactics to enhance their own self-interests, including emotionally manipulating their partner to attain sex (Muñoz et al., 2011). Psychopathy is reliably associated with an increased risk of violence, and Factor 1 traits have been associated with using violence instrumentally (Dhingra \& Boduszek, 2013). These findings are consistent with the traditional masculine norms violence and power over women. Traditional masculine norms have been associated with mating attempt rejection violence (Thacker, 2019) and sexually aggressive behaviour (Gerdes \& Levant, 2018). Factor 1 subclinical psychopathic traits have also been associated with social defection, dominance, and cost imposition when perceiving others as low value social partners (Gervais et al., 2013). Similarly, men endorsing traditional masculinity are often described as willing to marginalise and dominate others (Courtenay, 2000). Those individuals with high levels, relative to those with low levels, of subclinical psychopathic traits (across factors) make significantly more risky decisions in gambling tasks (Mahmut et al., 2008), aligning with the traditional masculine norms such as Risk-Taking and Need to Win. Individuals with high psychopathy lack empathy and remorse and appear to be undeterred by the possibility of hurting others (Glenn et al., 2009). This seems akin to a lack of concern for others which features often in definitions of traditional masculinity. Given this work, we could assume connections between psychopathy and certain masculine norms.

\section{Machiavellianism and masculinity}

Much like traditional masculinity, Machiavellianism has been associated with manipulative relationship behaviours, such as sexual deception and infidelity (Brewer \& Abell, 2015). Machiavellianism, along with narcissism and unrestricted socio-sexuality, positively predicted mating effort (Valentova et al., 2019). This increased effort towards obtaining mates aligns well with the traditional masculine norm Playboy (i.e., the desire for multiple sexual partners). Jewkes and Morrell (2018) determined that men of lower socioeconomic status experienced more childhood trauma which was 
associated with higher Machiavellian egocentricity scores. This, in turn, was associated with greater acceptance of violence in intimate relationships; again, Violence and Power over Women are traditional masculine norms. This indicates that men with higher levels of Machiavellian traits more actively seek romantic partners and are more likely to act abusively within those relationships. As research has not directly assessed the relationship between Machiavellianism and traditional masculinity, a goal is to empirically assess the nature and the extent of this overlap.

\section{Narcissism and masculinity}

Manipulative tactics are a feature of both trait narcissism and traditional masculinity. Trait narcissism has been associated with the use of emotionally controlling behaviours to maintain status and power (Campbell et al., 2011). These behaviours may stem from the difficulty narcissists have in maintaining social connections (Konrath et al., 2014), which is also a facet of traditional masculinity (i.e., Self-Reliance). Studies have shown that grandiose narcissism (i.e., self-inflation and admiration-seeking) is associated with aggressive and dangerous driving (Edwards et al., 2013; Hill, 2015) and engaging in risky behaviours (Buelow \& Brunell, 2014; Foster et al., 2009). Other studies have shown that pathological narcissism, which combines features of both grandiose and vulnerable narcissism (i.e., high neuroticism, low extraversion), is associated with aggressive behaviour (Ellison et al., 2013; Goldberg et al., 2007; Kealy et al., 2017). Risk-taking and aggression are key features of traditional masculinity. Jonason and Davis (2018) found that narcissism was associated with greater adherence to masculine gender roles. As such, and to achieve a more fine-grained understanding, it is worth assessing whether facets of trait narcissism are associated with certain facets of traditional masculinity (e.g., Need to Win). 


\section{Aims and Hypotheses}

As mentioned, direct relationships have not been established between DT traits and traditional masculinity. Although recent evidence (Van Doorn et al., 2020) has demonstrated that traditional masculinity is influenced by proximal social influences (i.e., contact with, and support from, friends over the past month), these influences explained only a small proportion of the variance in adherence to traditional masculine norms. The conceptual overlap between the DT and traditional masculinity suggests that adherence to traditional, negative masculine norms may be predicted by high levels of dark traits in men. The aim of this exploratory study is to assess whether facets of dark personality predict variation in adherence to several, traditional masculine norms. We expect that Factor 1 psychopathy (affective/interpersonal aspect), as a core feature of DT traits (e.g., Jones \& Figueredo, 2013), will be a dominant, positive predictor of many traditional masculine norms. Previous research suggests that the Erratic Lifestyle facet of psychopathy will be a significant, positive predictor of norms related to Risk-Taking (Mahmut et al., 2008) and Playboy (Brewer \& Abell, 2015). More generally, psychopathy will positively predict adherence to the traditional masculine norm Violence. It is further expected that narcissism will be a positive predictor of the Risk-Taking and Violence norms of traditional masculinity. Finally, it is expected that Machiavellianism will predict two norms, Playboy and Power over Women.

\section{Method}

\section{Participants}

Waddell et al.'s (2020) study established small-to-moderate relationships between DT traits and hegemonically-masculine norms, with effect sizes ranging from medium-to-large $\left(f^{2}=0.29-0.54\right)$. Using this as a guide, an a priorianalysis in $\mathrm{G}$ Power (Faul et al., 2009) indicated that a sample size of approximately 109 participants was required to detect medium-sized effects $\left(f^{2}=0.15\right)$ for regression analyses. 
Three hundred and fifty-eight English-speaking men logged into the online study. However, 121 respondents were excluded because they failed to answer at least half of the survey items. Consequently, data from 237 men (66.2\% of respondents) were analysed.

Missing values were present in the data due to participant nonresponse/drop-out. A missing values analysis showed that more than $5 \%$ of data were missing from certain items, but a Little's missing completely at random test was not statistically significant $(p=1.00)$. Thus, data were missing completely at random. Given these findings, five multiple imputations were performed to replace missing values. In all, 380 missing values were imputed.

Participants' ages ranged from 18 to 62 years $\left(M_{\text {age }}=31.13\right.$ years, $S D=$ 9.04), and all were in a romantic relationship. Ethical approval for this study was granted by Federation University Australia's Human Research Ethics Committee (project number: A20-073).

Instruments

Self-Report Psychopathy Scale - III (SRP-III)

Self-Report Psychopathy Scale - III (SRP-III; Williams et al., 2003). The SRP-III is a 64-item measure assessing non-clinical psychopathy including Factor 1 traits (i.e., Interpersonal Manipulation [IM], Callous Affect [CA]) and Factor 2 traits (Erratic Lifestyle [EL], Antisocial Behaviour [ASB]). Participants respond to items using a five-point Likert scale $(1=$ disagree strongly, $5=$ agree strong/y), and subscale scores are calculated by summing scores from the relevant items. Williams et al. (2003) demonstrated that the internal reliability for SRP-III subscales range from questionable-to-excellent (IM $\alpha=$ .76; CA $\alpha=.74$; EL $\alpha=.67$; ASB $\alpha=.91$;). In the current study, the internal consistency of the SRP-III's subscales ranged from acceptable-to-good (IM $\alpha$ $=.84 ; \mathrm{CA} \alpha=.77 ; \mathrm{EL} \alpha=.76 ; \mathrm{ASB} \alpha=.74)$. 
Mach-IV

Mach-IV (Christie \& Geis, 1970). The Mach-IV is a 20-item measure of Machiavellianism. The factor structure of the Mach-IV has been debated (see Monaghan et al., 2018), with some suggesting the three-factor structure (i.e., Interpersonal Tactics, Cynical View of Human Nature, and Disregard for Conventional Morality) is unstable. Consistent with this view, the internal consistency of the Mach-IV's subscales are less than impressive and are rarely reported (e.g., Interpersonal Tactics $\alpha=.68$; Cynical View $\alpha=.55$; Jones \& Figueredo, 2013). It is not surprising that the internal consistency of the Conventional Morality subscale is not reported as this subscale consists of only two items. In the current study, the correlation between the two items that contribute to the Conventional Morality subscale was very low $(r=0.06$, $p=.393)$, while the internal consistency of the subscales ranged from questionable-to-acceptable (Interpersonal Tactics $\alpha=.76$; Cynical View $\alpha=$ .69). As such, and consistent with Monahan et al. (2018), we assessed the reliability of the two-factor structure but found that the internal consistency of the Views subscale was questionable (Cronbach's alpha $=.63$ ). Consequently, and consistent with several other authors (e.g., Monahan et al., 2018) we use the Mach-IV total score. Participants respond to each item using a five-point Likert scale ( 1 = strongly disagree, 5 = strongly agree), and the total score was calculated by summing scores from all items. The internal consistency of the total score was good (Cronbach's $\alpha=.83$ ).

Narcissistic Personality Inventory (NPI)

Narcissistic Personality Inventory (NPI; Raskin \& Hall, 1981). The NPI is a 40-item personality measure assessing non-clinical levels of trait narcissism consisting to five factors (Dinić \& Vujić 2019). This study used a Likert response format as opposed to a forced-choice format, as recommended and validated by Miller et al. (2018). Participants respond to each item using a five-point Likert scale $(1=$ strongly disagree, 5 = strongly agree). Using a Likert style response format has been shown to increase the internal consistency of the $\mathrm{NPI}$, with prior research finding the internal consistency of the factors was acceptable-to-excellent (i.e., Leadership $\alpha=.90$; Exhibitionism $\alpha=.83$; Vanity 
$\alpha=.84$; Manipulativeness $\alpha=.84$; Superiority $\alpha=.79$; Dinić \& Vujić 2019). The internal consistency of the NPI factors in the current study were acceptableto-good (Leadership $\alpha=.88$; Exhibitionism $\alpha=.76$; Vanity $\alpha=.85$; Manipulativeness $\alpha=.79$; and Superiority $\alpha=.78$ ).

The Conformity to Masculine Norms Inventory-29 (CMNI-29)

The Conformity to Masculine Norms Inventory-29 (CMNI-29; Hsu \& Iwamoto, 2014). The CMNI-29 was used to assess the extent to which men conform to traditional masculine norms of Playboy, Self-Reliance, Emotional Control, Winning, Violence, Heterosexual Self-Presentation, Risk-Taking, and Power over Women. The measure comprises 29 items with responses recorded on a four-point Likert-type scale ( 0 = strongly disagree, 3 = strongly agree). The CMNI-29 was chosen because its subscales have acceptable-togood internal reliability (i.e., Cronbach's alphas range from .71 to .87; Hsu \& Iwamoto, 2014). In the current study, the internal consistency of the CMNI29's subscales ranged from acceptable-to-excellent (Playboy $\alpha=.82$; SelfReliance $\alpha=.85$; Emotional Control $\alpha=.91$; Winning $\alpha=.82$; Violence $\alpha=.81$; Heterosexual Self-Presentation $\alpha=.90$; Risk-Taking $\alpha=.77$; Power over Women $\alpha=.81)$.

\section{Procedure}

English-speaking men aged 18 years and older were invited to participate in the survey via posts on social media platforms (i.e., Facebook, Twitter, Reddit, and Instagram), and snowballing. Although this might be considered convenience sampling, and thus bias the results, we refer the reader to Coppock et al. (2018) who demonstrated that effects estimated from surveys conducted using online convenience samples are very similar to those estimated from nationally representative samples.

Those interested in participating followed a link to the survey's landing page on Qualtrics ${ }^{\mathrm{TM}}$. Here, participants read an information statement which, amongst other things, outlined the anonymous nature of the survey and each person's right to withdraw from the study at any time. Participants 
provided informed consent by clicking an "I agree" button. At this point, they were taken to the survey proper. Here, participants were asked to complete demographic questions before completing the SRP-III, NPI, MACH-IV, and CMNI-29 in random order. When finished, a debriefing statement was presented, and participants were asked to re-affirm their consent. The survey took approximately 15 minutes to complete. No incentives were offered for participating.

Results

Table 1 presents descriptives of, and bivariate correlations between, all variables. The bivariate correlations between traditional masculine norms and psychopathy suggest that men scoring high on Risk-Taking, Violence, and Power over Women were high on all facets of psychopathy. Likewise, men scoring high on the Need to Win, Risk-Taking, Heterosexual Self-Presentation, Emotional Control, Violence, Playboy, and Power over Women were high on Machiavellianism. The bivariate correlations between traditional masculine norms and narcissism suggest that men scoring high on the Need to Win, RiskTaking, and Power over Women were high on the Leadership and Superiority facets of narcissism, while those high on Self-Reliance were low on these facets. 


\section{Table 1}

Correlation Matrix between Masculine Norms, Psychopathy, Machiavellianism, and Narcissism

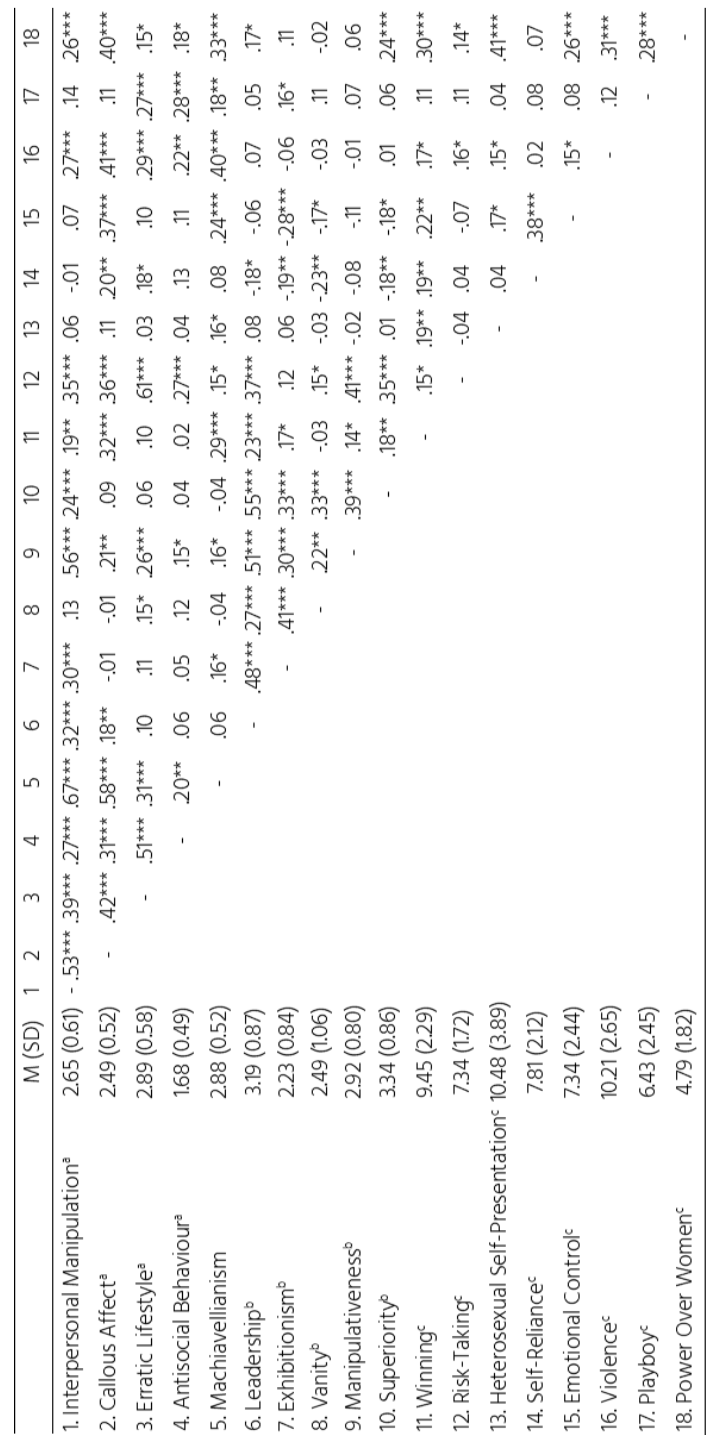

Notes: apsychopathy subscales, ${ }^{b}$ Narcissism subscales, ${ }^{c}$ Masculine norms, ${ }^{\star} p<.05$, ${ }^{\star *} p<.01,{ }^{* \star *} p<.001$. 


\section{Inferential Analyses}

Prior to running inferential analyses, assumptions were assessed. All assumptions (e.g., sample size, normality, linearity, multicollinearity, homoscedasticity) were met. Multiple linear regression analyses were run with the outcome variables being traditional masculine norms (e.g., RiskTaking) and dark traits as predictors (Table 2).

\section{Table 2}

Regression models for the Need to Win, Risk-Taking, Heterosexual Self-Presentation, and Self-Reliance

\begin{tabular}{|c|c|c|c|c|c|}
\hline \multirow[b]{2}{*}{ Variables } & \multirow[b]{2}{*}{$B$} & \multirow[b]{2}{*}{ Std Error(B) } & \multicolumn{2}{|c|}{$95 \% \mathrm{Cl}(B)$} & \multirow[b]{2}{*}{$\beta$} \\
\hline & & & Lower & Upper & \\
\hline \multicolumn{6}{|l|}{ Need to Win } \\
\hline \multicolumn{6}{|c|}{$F(10,226)=4.06, p<.001, R^{2}=.152$} \\
\hline Constant & 4.09 & 1.21 & - & - & - \\
\hline Interpersonal Manipulation ${ }^{a}$ & -0.07 & 0.29 & -0.66 & 0.52 & -.20 \\
\hline Callous Affect ${ }^{a}$ & 0.80 & 0.36 & 0.09 & 1.51 & $.29^{*}$ \\
\hline Erratic Lifestyle ${ }^{a}$ & 0.06 & 0.29 & -0.52 & 0.63 & .01 \\
\hline Antisocial Behaviour ${ }^{a}$ & -0.32 & 0.31 & -0.93 & 0.30 & -.08 \\
\hline Machiavellianism & 0.73 & 0.43 & -0.14 & 1.60 & .21 \\
\hline Leadership ${ }^{b}$ & 0.31 & 0.24 & -0.16 & 0.78 & .09 \\
\hline Exhibitionism $^{b}$ & 0.27 & 0.22 & -0.16 & 0.70 & .16 \\
\hline Vanity $^{\mathrm{b}}$ & -0.24 & 0.16 & -0.54 & 0.07 & -.17 \\
\hline Manipulativeness ${ }^{\mathrm{b}}$ & -0.09 & 0.24 & -0.57 & 0.39 & .03 \\
\hline Superiority ${ }^{b}$ & 0.32 & 0.21 & -0.10 & 0.73 & .18 \\
\hline \multicolumn{6}{|l|}{ Risk-Taking } \\
\hline \multicolumn{6}{|l|}{$F(10,226)=12.91, p<.001, R^{2}=.363$} \\
\hline Constant & 0.94 & 0.80 & - & - & - \\
\hline Interpersonal Manipulation ${ }^{a}$ & 0.04 & 0.19 & -0.35 & 0.42 & -.02 \\
\hline Callous Affect ${ }^{a}$ & 0.37 & 0.25 & -0.14 & 0.87 & .09 \\
\hline Erratic Lifestyle & 0.89 & 0.19 & 0.52 & 1.27 & $.58^{\star \star \star}$ \\
\hline Antisocial Behaviour ${ }^{\mathrm{a}}$ & 0.25 & 0.22 & -0.20 & 0.69 & -.06 \\
\hline Machiavellianism & -0.07 & 0.24 & -0.55 & 0.41 & -.05 \\
\hline
\end{tabular}




\begin{tabular}{|c|c|c|c|c|c|}
\hline Leadership $^{\mathrm{b}}$ & 0.36 & 0.16 & 0.03 & 0.68 & $.19^{*}$ \\
\hline Exhibitionism ${ }^{b}$ & -0.25 & 0.15 & -0.54 & 0.05 & -.14 \\
\hline Vanity $^{b}$ & -0.01 & 0.11 & -0.23 & 0.21 & -.02 \\
\hline Manipulativeness ${ }^{b}$ & 0.34 & 0.17 & 0.01 & 0.68 & $.13^{*}$ \\
\hline Superiority ${ }^{b}$ & 0.31 & 0.14 & 0.04 & 0.57 & $.21^{*}$ \\
\hline \multicolumn{6}{|l|}{ Heterosexual Self-Presentation } \\
\hline \multicolumn{6}{|c|}{$F(10,226)=0.96, p=.483, R^{2}=.041$} \\
\hline Constant & 7.12 & 2.17 & - & - & - \\
\hline Interpersonal Manipulation ${ }^{\mathrm{a}}$ & -0.14 & 0.55 & -1.27 & 0.99 & -.11 \\
\hline Callous Affect ${ }^{\mathrm{a}}$ & 0.22 & 0.79 & -1.42 & 1.85 & .00 \\
\hline Erratic Lifestyle ${ }^{a}$ & -0.10 & 0.62 & -1.40 & 1.21 & -.04 \\
\hline Antisocial Behaviour ${ }^{\mathrm{a}}$ & 0.13 & 0.73 & -1.36 & 1.61 & .03 \\
\hline Machiavellianism & 1.04 & 0.74 & -0.43 & 2.52 & .25 \\
\hline Leadership ${ }^{b}$ & 0.55 & 0.43 & -0.29 & 1.39 & .15 \\
\hline Exhibitionism ${ }^{b}$ & 0.12 & 0.41 & -0.70 & 0.93 & -.05 \\
\hline Vanity $^{\mathrm{b}}$ & -0.12 & 0.30 & -0.70 & 0.46 & .06 \\
\hline Manipulativeness ${ }^{b}$ & -0.51 & 0.45 & -1.41 & 0.38 & -.04 \\
\hline Superiority ${ }^{b}$ & -0.01 & 0.39 & -0.77 & 0.76 & -.03 \\
\hline \multicolumn{6}{|l|}{ Self-Reliance } \\
\hline \multicolumn{6}{|l|}{$F(10,226)=3.47, p<.001, R^{2}=.133$} \\
\hline Constant & 7.80 & 1.05 & - & - & - \\
\hline Interpersonal Manipulation ${ }^{a}$ & -0.04 & 0.25 & -0.54 & 0.46 & -.13 \\
\hline Callous Affect ${ }^{\mathrm{a}}$ & 0.63 & 0.34 & 0.04 & 1.30 & .24 \\
\hline Erratic Lifestyle ${ }^{a}$ & 0.29 & 0.27 & -0.27 & 0.84 & .11 \\
\hline Antisocial Behaviour ${ }^{\mathrm{a}}$ & 0.31 & 0.32 & -0.33 & 0.94 & .05 \\
\hline Machiavellianism & -0.11 & 0.35 & -0.78 & 0.57 & -.02 \\
\hline Leadership ${ }^{b}$ & -0.29 & 0.23 & -0.73 & 0.16 & -.15 \\
\hline Exhibitionism ${ }^{b}$ & -0.10 & 0.21 & -0.51 & 0.31 & .01 \\
\hline Vanity $^{b}$ & -0.35 & 0.15 & -0.65 & -0.04 & $-.18 *$ \\
\hline Manipulativeness ${ }^{b}$ & -0.03 & 0.22 & -0.46 & 0.40 & .05 \\
\hline Superiority ${ }^{b}$ & -0.13 & 0.20 & -0.51 & -0.26 & -.07 \\
\hline
\end{tabular}

Notes: ${ }^{a}$ Psychopathy subscales, ${ }^{b}$ Narcissism subscales, ${ }^{\star} p<.05,{ }^{\star \star} p<.01,{ }^{\star \star \star} p<.001$.

Table 2 shows that the DT traits accounted for $15 \%$ of the variance in men's Need to Win. Callous Affect was the only statistically significant 
predictor of the Need to Win. Table 2 also shows that the model accounted for $36 \%$ of the variance in Risk-Taking. Erratic Lifestyle and the narcissism subscales Leadership, Manipulativeness, and Superiority were statistically significant predictors of Risk-Taking. The model associated with Heterosexual Self-Presentation (Table 2) accounted for $4 \%$ of the variance. None of the DT traits were statistically significant predictors of Heterosexual SelfPresentation. Lastly, Table 2 shows that the model accounted for $13 \%$ of the variance in men's Self-Reliance. Vanity was the only statistically significant predictor of Self-Reliance. Table 3 shows models predicting Emotional Control, Violence, Playboy, and Power over Women.

\section{Table 3}

Regression models for Emotional Control, Violence, Playboy, and Power over Women

\begin{tabular}{|c|c|c|c|c|c|}
\hline \multirow[b]{2}{*}{ Variables } & \multirow[b]{2}{*}{$B$} & \multirow[b]{2}{*}{ Std Error(B) } & \multicolumn{2}{|c|}{$95 \% C l(B)$} & \multirow[b]{2}{*}{$\beta$} \\
\hline & & & Lower & Upper & \\
\hline \multicolumn{6}{|l|}{ Emotional Control } \\
\hline \multicolumn{6}{|c|}{$F(10,226)=5.87, p<.001, R^{2}=.206$} \\
\hline Constant & 5.52 & 1.13 & - & - & - \\
\hline Interpersonal Manipulation ${ }^{a}$ & 0.08 & 0.31 & -0.55 & 0.72 & -.21 \\
\hline Callous Affect ${ }^{\mathrm{a}}$ & 1.16 & 0.43 & 0.27 & 2.06 & $.33^{*}$ \\
\hline Erratic Lifestyle & 0.01 & 0.28 & -0.55 & 0.57 & -.04 \\
\hline Antisocial Behaviour ${ }^{\mathrm{a}}$ & 0.04 & 0.33 & -0.61 & 0.69 & .06 \\
\hline Machiavellianism & 0.50 & 0.39 & -0.27 & 1.28 & .21 \\
\hline Leadership ${ }^{\mathrm{b}}$ & 0.37 & 0.24 & -0.10 & 0.85 & .14 \\
\hline Exhibitionism ${ }^{b}$ & -0.76 & 0.22 & -1.20 & -0.32 & $-.29 * * \star$ \\
\hline Vanity ${ }^{b}$ & -0.07 & 0.16 & -0.39 & 0.27 & .05 \\
\hline Manipulativeness ${ }^{b}$ & -0.32 & 0.24 & -0.78 & 0.15 & -.03 \\
\hline Superiority ${ }^{b}$ & -0.36 & 0.21 & -0.78 & 0.06 & -.15 \\
\hline \multicolumn{6}{|l|}{ Violence } \\
\hline \multicolumn{6}{|c|}{$F(10,226)=5.80, p<.001, R^{2}=.204$} \\
\hline Constant & 3.53 & 1.33 & - & - & - \\
\hline Interpersonal Manipulation ${ }^{a}$ & 0.15 & 0.31 & -0.48 & 0.77 & .02 \\
\hline Callous Affect ${ }^{\mathrm{a}}$ & 0.82 & 0.39 & 0.05 & 1.60 & $.15^{*}$ \\
\hline
\end{tabular}




\begin{tabular}{|c|c|c|c|c|c|}
\hline Erratic Lifestyle ${ }^{a}$ & 0.47 & 0.32 & -0.17 & 1.10 & .12 \\
\hline Antisocial Behaviour ${ }^{a}$ & 0.35 & 0.37 & -0.38 & 1.08 & .05 \\
\hline Machiavellianism & 1.17 & 0.44 & 0.29 & 2.05 & $.31^{*}$ \\
\hline Leadership $^{b}$ & 0.46 & 0.27 & -0.07 & 1.00 & .14 \\
\hline Exhibitionismb & -0.45 & 0.24 & -0.92 & 0.02 & -.19 \\
\hline Vanity $^{\mathrm{b}}$ & -0.01 & 0.17 & -0.35 & 0.33 & .03 \\
\hline Manipulativeness $^{b}$ & -0.57 & 0.28 & -1.13 & -0.01 & $-.16^{\star}$ \\
\hline Superiority ${ }^{b}$ & 0.05 & 0.25 & -0.45 & 0.54 & .05 \\
\hline \multicolumn{6}{|l|}{ Playboy } \\
\hline \multicolumn{6}{|c|}{$F(10,226)=2.78, p=.003, R^{2}=.110$} \\
\hline Constant & 1.89 & 1.25 & - & - & - \\
\hline Interpersonal Manipulation ${ }^{a}$ & -0.17 & 0.51 & -1.37 & 1.02 & -.15 \\
\hline Callous Affect ${ }^{\mathrm{a}}$ & -0.17 & 0.38 & -0.93 & 0.59 & -.09 \\
\hline Erratic Lifestyle $^{a}$ & 0.38 & 0.42 & -0.56 & 1.31 & .13 \\
\hline Antisocial Behaviour ${ }^{\mathrm{a}}$ & 0.97 & 0.41 & 0.13 & 1.80 & $.20^{*}$ \\
\hline Machiavellianism & 0.67 & 0.50 & -0.38 & 1.71 & .23 \\
\hline Leadership ${ }^{b}$ & -0.09 & 0.26 & -0.60 & 0.42 & -.02 \\
\hline Exhibitionism ${ }^{b}$ & 0.37 & 0.24 & -0.10 & 0.83 & .09 \\
\hline$V$ anity ${ }^{b}$ & 0.04 & 0.17 & -0.30 & 0.38 & .09 \\
\hline Manipulativeness ${ }^{b}$ & -0.07 & 0.28 & -0.64 & 0.49 & .03 \\
\hline Superiority ${ }^{b}$ & 0.12 & 0.23 & -0.33 & 0.59 & .01 \\
\hline \multicolumn{6}{|l|}{ Power over Women } \\
\hline \multicolumn{6}{|c|}{$F(10,226)=6.77, p<.001, R^{2}=.230$} \\
\hline Constant & -0.28 & 0.89 & - & - & - \\
\hline Interpersonal Manipulation ${ }^{\mathrm{a}}$ & 0.01 & 0.23 & -0.47 & 0.48 & -.05 \\
\hline Callous Affect ${ }^{\mathrm{a}}$ & 0.91 & 0.31 & 0.27 & 1.55 & $.30^{* *}$ \\
\hline Erratic Lifestyle $^{a}$ & -0.03 & 0.22 & -0.48 & 0.42 & -.08 \\
\hline Antisocial Behaviour ${ }^{\mathrm{a}}$ & 0.25 & 0.24 & -0.23 & 0.73 & .08 \\
\hline Machiavellianism & 0.53 & 0.34 & -0.18 & 1.24 & .19 \\
\hline Leadership $^{b}$ & 0.04 & 0.18 & -0.31 & 0.39 & .03 \\
\hline Exhibitionism ${ }^{b}$ & 0.16 & 0.18 & -0.20 & 0.51 & .04 \\
\hline$V$ anity ${ }^{b}$ & -0.17 & 0.13 & -0.42 & 0.08 & -.09 \\
\hline Manipulativeness ${ }^{b}$ & -0.32 & 0.19 & -0.68 & 0.05 & -.07 \\
\hline Superiority ${ }^{b}$ & 0.55 & 0.16 & 0.24 & 0.87 & $.28^{\star \star \star}$ \\
\hline
\end{tabular}

Notes: apsychopathy subscales, ${ }^{b}$ Narcissism subscales, ${ }^{\star} p<.05,{ }^{\star *} p<.01,{ }^{\star \star \star} p<.001$. 
Table 3 shows that the model accounted for $21 \%$ of the variance in the traditional masculine norm Emotional Control. The psychopathic trait of Callous Affect and the narcissistic trait of Exhibitionism were statistically significant predictors of Emotional Control. Table 3 also shows that the model accounted for $20 \%$ of the variance in Violence, with the psychopathic trait of Callous Affect, Machiavellianism, and the narcissistic trait of Manipulativeness being statistically significant predictors. The model accounted for $11 \%$ of the variance in Playboy, and Table 3 shows that the only statistically significant predictor was the psychopathic trait of Antisocial Behaviour. Finally, Table 3 shows that the model accounted for $23 \%$ of the variance in Power over Women, with the narcissistic trait of Superiority and the psychopathic trait of Callous Affect being the only statistically significant predictors.

\section{Discussion}

Building on previous research (Jonason \& Davis, 2018), we found partial support for the hypothesis that Erratic Lifestyle (psychopathy) would positively predict the Risk-Taking and Playboy norms. Erratic Lifestyle did predict Risk-Taking but failed to explain variance in Playboy. We also partially supported the hypothesis that psychopathy would positively predict the Violence norm in that Callous Affect significantly predicted Violence. It was also expected that narcissism would be a positive predictor of the Risk-Taking and Violence norms. This hypothesis was supported. The narcissistic traits Leadership, Manipulativeness, and Superiority predicted Risk-Taking, while Manipulativeness predicted Violence. Interestingly, Superiority predicted Power over Women, Vanity predicted Self-Reliance, and Exhibitionism predicted Emotional Control. We hypothesised that Machiavellianism would predict Playboy and Power over Women. This was not supported in that Machiavellianism only explained variance in Violence. More generally, psychopathy Factor 1 was hypothesised to be a positive predictor of many traditional masculine norms. Callous Affect predicted Winning, Emotional Control, Violence, and Power over Women, supporting expectations. However, Interpersonal Manipulation failed to predict any facets of 
traditional masculinity. Further, neither Callous Affect nor Interpersonal Manipulation were significant predictors of Playboy or Heterosexual SelfPresentation.

\section{Psychopathy and masculinity}

In men, the psychopathic trait of Callous Affect predicted the Need to Win, Emotional Control, Violence, and Power over Women. In relation to the Need to Win, Iwamoto and Smiler (2013) described this norm as "the drive to win at all costs" (p. 372). Being callous would seem to benefit an individual whose aim was winning at all costs. Being callous would also likely increase the use of instrumental violence (Dhingra \& Boduszek, 2013). Individuals with high levels of psychopathy use coercive tactics to enhance their own selfinterests, including emotionally manipulating their partner to attain sex (Muñoz et al., 2011). We have found that it is Callous Affect that contributes to men's need to maintain Power over Women. Further, Callous Affect was a statistically significant predictor of Emotional Control. Callousness and a lack of empathy are core features of the psychopathic construct (Verschuere et al., 2018). Psychopathy is also reliably related to diminished or aberrant affective response (Pfabigan et al., 2015). Thus, it is not unrealistic to suggest that controlling one's own emotions probably requires one to be insensitive and possibly even cruel. Courtenay (2000) argued that men demonstrate masculinity by denying emotions and associate the expression of emotions with weakness (see also Emslie et al., 2006). However, the association between callous affect and emotional control found here suggests that this aspect of traditional masculinity is, at least partially, explained by a reduced affective capacity. Jones and Figueredo (2013) suggest that the DT traits share a common core represented by the facets of Hare's (2003) Factor 1 (i.e., Interpersonal Manipulation and Callous Affect). As such, being high on the callousness aspect of the dark 'core' may explain why certain men adhere to traditional masculine norms such as feeling the Need to win, engaging in more risky decisions, being more self-reliant and emotionally controlled, exerting power over women, and using violence. 


\section{Machiavellianism and masculinity}

Machiavellianism was a statistically significant predictor of Violence. Previous research has shown inconsistent relationships between Machiavellianism and violence. For example, Kiire (2019) found a weak, positive, bivariate correlation between Machiavellianism and sexual violence. Whereas, in a study of violence in intimate partnerships, Plouffe et al. (2020) found that neither Machiavellianism nor psychopathy or narcissism predicted men's perpetration of violence. Further, Pailing et al. (2014) found that after controlling for the HEXACO personality traits of honesty/humility and agreeableness, psychopathy but not Machiavellianism nor narcissism predicted self-reported violence. These differences in the association between Machiavellianism and violence may be due to differences in the measurement of violence. For example, when measuring violence, Pailing et al. used a modified measure in which participants self-reported the frequency with which they have committed acts of violence. In the current study, the violence norm subscale of the CMNI-29 (Hsu \& Iwamoto, 2014) measures participants agreement with statements concerning the permissibility of violent behaviour. It may be the case that increased levels of Machiavellianism result in more accepting attitudes towards the use of violence without increases in the perpetration of violence.

\section{Narcissism and masculinity}

The facets of narcissism were significant predictors of Risk-Taking, Self-Reliance, Emotional Control, Violence, and Power over Women. Consistent with previous research, (grandiose) narcissism has been associated with engaging in risky behaviours (Buelow \& Brunell, 2014). Foster et al. (2009) demonstrated that narcissists "appreciate the risks associated with risky behaviors" (p. 885) but engage in these behaviours despite the risks because they believe there are rewards associated with them. Further, results showing that the Superiority facet of narcissism is a positive predictor of masculine Control over Women are consistent with the findings of previous research. For example, Tetreault et al. (2018) show that men's narcissism 
predicted the use of explosive aggression in intimate partnerships. Similarly, Kiire (2019) found that narcissism was a positive predictor of intimate partner control and stalking, as well as sexual violence. Overall, and consistent with Jonason and Davis's (2018) work on adherence to masculine gender roles, the findings suggest that narcissism is associated with greater adherence to many traditional masculine norms.

\section{Limitations and Future Directions}

Although a substantial proportion of the variance in risk-taking was explained, it would be useful to identify other predictors of traditional masculine norms. Previous research has demonstrated that psychopathy Factor 1 can be used to represent, and make predictions about, the Dark Core of the DT (Jones \& Figueredo, 2013). Using Factor 1 as the analogue of the Dark Core, we found that Callous Affect predicted several traditional masculine norms. However, we also found that DT traits individually and differentially predict adherence to, and endorsement of, traditional masculine norms. What is not shown through these predictive associations between the DT traits and subscales of the CMNI-29 (Hsu \& Iwamoto, 2014) is whether the increased adherence to, and endorsement of, these masculine norms result in behavioural outcomes. Differences between our findings and the findings of past research (i.e., Machiavellianism and violence) indicate that this may not be the case. Future research should endeavour to assess whether increases in DT traits are predictive of behavioural outcomes that would be expected if one adhered to traditional masculine norms. Also, and given disagreement in the literature concerning the factor structure of the NPI (Ackerman et al., 2011; Kubarych et al., 2004), we used a five factor structure of narcissism. Future research could measure grandiose and vulnerable narcissism and assess whether they explain unique variance in traditional masculine norms. Finally, the Mach-IV Disregard for Conventional Morality subscale consists of only two items. In this exploratory study, we found that these two items share a very low correlation with each other. In future, researchers should consider 
further developing this subscale to ensure that it accesses the construct with increased reliability and construct validity.

\section{Concluding Comments}

We found that different features of dark traits predict men's adherence to traditional masculine norms. To reiterate, the (a) psychopathic trait of Callous Affect was the only significant predictor of the Need to Win, (b) psychopathic trait of Erratic Lifestyle and the narcissistic traits of Leadership, Manipulativeness, and Superiority were significant predictors of Risk-Taking, (c) psychopathic trait of Callous Affect, Machiavellianism, and the narcissistic trait of Manipulativeness were significant predictors of Violence, (d) psychopathic trait of Antisocial Behaviour was the only significant predictor of Playboy, (e) narcissistic trait of Vanity was the only significant predictor of Self-Reliance, (f) psychopathic trait of Callous Affect and the narcissistic trait of Superiority were significant predictors of Power over Women, and (g) psychopathic trait of Callous Affect and the narcissistic trait of Exhibitionism were significant predictors of Emotional Control. As several dark traits appear to be good predictors of endorsement of traditional masculine norms, our findings have implications for interventions aimed at addressing problematic behaviours (e.g., violence) associated with gender norms. That is, interventions that fail to address the dark traits associated with adherence to these traditional masculine norms might prove ineffective (see Grieve \& Mahar, 2010, for a similar argument).

\section{Acknowledgement}

We thank those people who took the time to participate in this study.

\section{Ethics approval and consent to participate}

This study was approved by Federation University's Human Research Ethics Committee (HREC A20-073). All participants were older than 18 years of age. They were informed as to the aim of the study and informed consent was obtained prior to data collection. They were also informed that they had the right to withdraw from the study at any time. No financial incentive was 
offered for their participation. Data was provided anonymously. The authors agree with the ethical standards of publication in Primenjena psihologija. Conflicts of interest

The authors declare they have no conflict of interest.

Data Availability Statement

The data presented in this study are available on request from the corresponding author. The data are not publicly available due to ethical restrictions.

\section{References}

Ackerman, R.A., Witt, E.A., Donnellan, M.B., Trzesniewski, K.H., Robins, R.W., \& Kashy, D.A. (2011). What does the Narcissistic Personality Inventory really measure? Assessment, 18, 67-87.

\section{https://doi.org/10.1177/1073191110382845}

Brewer, G., \& Abell, L. (2015). Machiavellianism and sexual behavior: Motivations, deception and infidelity. Personality and Individual Differences, 74, 186191. https://doi.org/10.1016/.jpaid.2014.10.028

Buelow, M.T., \& Brunell, A.B. (2014). Facets of grandiose narcissism predict involvement in health-risk behaviors. Personality \& Individual Differences, 69, 193-198. https://doi.org/10.1016/j.paid.2014.05.031

Caligor, E., Levy, K.N., \& Yeomans, F.E. (2015). Narcissistic personality disorder: Diagnostic and clinical challenges. American Journal of Psychiatry, 172, 415-422. https://doi.org/10.1176/appi.ajp.2014.14060723

Campbell, W.K., Hoffman, B.J., Campbell, S.M., \& Marchisio, G. (2011). Narcissism in organizational contexts. Human Resource Management Review, 21, 268284. https://doi.org/10.1016/j.hrmr.2010.10.007

Carrigan, T., Connell, B., \& Lee, J. (1985). Toward a new sociology of masculinity. Renewal and Critique in Social Theory, 14(5), 551-604. https://doi.org/10.1007/BF00160017 
Christie, R. \& Geis, F. (1970). Implications and speculations. In R. Christie \& F.L. Geis (Eds.), Studies in Machiavellianism (pp. 350-358). New York: Academic Press.

Connell, R. (2005). Masculinities (2nd ed.). Academic.

Connell, R. (2016) Masculinities in global perspective: Hegemony, contestation, and changing structures of power. Theory and Society, 45(4), 303-318. https://doi.org/10.1007/s11186-016-9275-x

Connell, R.W. (1987). Gender and power: Society, the person, and sexual politics. Sydney, Australia: Allen \& Unwin.

Connell, R.W. (2000). The men and the boys. United Kingdom: Polity Press. Coppock, A., Leeper, T.J., \& Mullinix, K.J. (2018). Generalizability of heterogeneous treatment effect estimates across samples. Proceedings of the National Academy of Sciences of the United States of America, 115(49), 1244112446. https://doi.org/10.1073/pnas.1808083115

Courtenay, W.H. (2000). Constructions of masculinity and their influence on men's well-being: A theory of gender and health. Social Science \& Medicine, 50, 1385-1401. https://doi.org/10.1016/S0277-9536(99)00390-1

Dhingra, K., \& Boduszek, D. (2013). Psychopathy and criminal behaviour: A psychosocial research perspective. Journal of Criminal Psychology, 3(2), 83-107. https://doi.org/10.1108/JCP-06-2013-0014

Dinić, B. M., \& Vujić, A. (2019). Five-factor model best describes Narcissistic Personality Inventory across different item response formats. Psychological Reports, 122(5), 1946-1966.

\section{https://doi.org/10.1177/0033294118794404}

Donaldson, M. (1993). What is Hegemonic Masculinity? Theory and Society, 22, 643-657. https://doi.org/10.1007/BF00993540

Edwards, B.D., Warren, C.R., Tubré, T.C., Zyphur, M.J., Hoffner-Prillaman, R. (2013). The validity of narcissism and driving anger in predicting aggressive driving in a sample of young drivers. Human Performance, 26, 191-210. https://doi.org/10.1080/08959285.2013.795961 
Ellison, W.D., Levy, K.N., Cain, N.M., Ansell, E.B., Pincus, A.L. (2013). The impact of pathological narcissism on psychotherapy utilization, initial symptom severity, and early-treatment symptom change: A naturalistic investigation. Journal of Personality Assessment, 95, 291-300. https://doi.org/10.1080/00223891.2012.742904

Emslie, C., Ridge, D., Ziebland, S., \& Hunt, K. (2006). Men's accounts of depression: Reconstructing or resisting hegemonic masculinity? Social Science \& Medicine, 62, 2246-2257. https://doi.org/10.1016/j.socscimed.2005.10.017

Faul, F., Erdfelder, E., Buchner, A., \& Lang, A.G. (2009) Statistical power analyses using G*Power 3.1: Tests for correlation and regression analyses. Behavior Research Methods, 41, 1149-1160. http://dx.doi.org/10.3758/BRM.41.4.1149

Foster, J.D., Shenesey, J.W., \& Goff, J.S. (2009). Why do narcissists take more risks? Testing the roles of perceived risks and benefits of risky behaviors. Personality and Individual Difference, 47, 885-889.

\section{https://doi.org/10.1016/.jpaid.2009.07.008}

Geis, F.L., \& Levy, M. (1970). The eye of the beholder. In R. Christie \& F.L. Geis (Eds.), Studies in Machiavellianism (pp. 210-211). New York: Academic Press.

Gerdes, Z.T., \& Levant, R.F. (2018). Complex relationships among masculine norms and health/well-being outcomes: Correlation patterns of the Conformity to Masculine Norms Inventory subscales. American journal of men's health, 12(2), 229-240. https://doi.org/10.1177/1557988317745910

Gervais, M.M., Kline, M., Ludmer, M., George, R., \& Manson, J.H. (2013). The strategy of psychopathy: Primary psychopathic traits predict defection on low-value relationships. Proceedings of the Royal Society B:

Biological Sciences, 280(1757), 20122773.

https://doi.org/10.1098/rspb.2012.2773 
Glenn, A.L., Raine, A., \& Schug, R.A. (2009). The neural correlates of moral decision-making in psychopathy. Molecular Psychiatry, 14, 5-6. https://doi.org/10.1038/mp.2008.104

Goldberg, B.R., Serper, M.R., Sheets, M., Beech, D., Dill, C., \& Duffy, K.G. (2007). Predictors of aggression on the psychiatric inpatient service: Selfesteem, narcissism, and theory of mind deficits. The Journal of Nervous and Mental Disease, 195, 436-442.

\section{https://doi.org/10.1097/01.nmd.0000253748.47641.99}

Gordon, D.M., Hawes, S.W., Reid, A.E., Callands, T.A., Magriples, U., Divney, A., Niccolai, L.M., \& Kershaw, T. (2013). The many faces of manhood: Examining masculine norms and health behaviors of young fathers across race. American Journal of Men's Health, 75), 394-401. https://doi.org/10.1177/1557988313476540

Grieve, R., \& Mahar, D. (2010). The emotional manipulation-psychopathy nexus: Relationships with emotional intelligence, alexithymia and ethical position. Personality and Individual Differences, 48, 945-950.

https://doi.org/10.1016/j.paid.2010.02.028

Hare, R.D. (2003). The Hare psychopathy checklist-revised ( $2^{\text {nd }}$ ed). Toronto, ON: Multi-Health Systems.

Hare, R.D., \& Neumann, C.S. (2008). Psychopathy as a clinical and empirical construct. Annual Review of Clinical Psychology, 4, 217-246.

https://doi.org/10.1146/annurev.clinpsy.3.022806.091452

Heym, N., Firth, J., Kibowski, F., Sumich, A., Egan, V., \& Bloxsom, C.A. (2019). Empathy at the heart of darkness: Empathy deficits that bind the Dark Triad and those that mediate indirect relational aggression. Frontiers in Psychiatry, 10, 1-10. https://doi.org/10.3389/fpsyt.2019.00095

Hill, E.M. (2015). The role of narcissism in health-risk and health-protective behaviors. Journal of Health Psychology, 21(9), 2021-2032. http://dx.doi.org/10.1177/1359105315569858. 
Hsu, K., \& Iwamoto, D.K. (2014). Testing for measurement invariance in the Conformity to Masculine Norms-46 across White and Asian American college men: Development and validity of the CMNI-29. Psychology of Men \& Masculinity, 15(4), 397-406. https://doi.org/10.1037/a0034548 Iwamoto, D.K., \& Smiler, A.P. (2013). Alcohol makes you macho and helps you make friends: The role of masculine norms and peer pressure in adolescent boys' and girls' alcohol use. Substance Use \& Misuse, 48(5), 371-378. https://doi.org/10.3109/10826084.2013.765479

Jewkes, R., \& Morrell, R. (2018). Hegemonic masculinity, violence, and gender equality: Using Latent Class Analysis to investigate the origins and correlates of differences between men. Men and Masculinities, 21(4), 547-571. https://doi.org/10.1177/1097184X17696171

Jewkes, R., Morrell, R., Hearn, J., Lundqvist, E., Blackbeard, D., Lindegger, G., Quayle, M., Sikweyiya, Y., \& Gottzén, L. (2015). Hegemonic masculinity: Combining theory and practice in gender interventions. Culture, Health \& Sexuality, 7, 96-111. https://doi.org/10.1080/13691058.2015.1085094 Jonason, P.K., \& Davis, M.D. (2018). A gender role view of the Dark Triad traits. Personality and Individual Differences, 125, 102-105.

https://doi.org/10.1016/j.paid.2018.01.004 Jonason, P.K., Li, N.P., \& Buss, D.M. (2010). The costs and benefits of the Dark Triad: Implications for mate poaching and mate retention tactics. Personality and Individual Differences, 48(4), 373-378.

\section{https://doi.org/10.1016/j.paid.2009.11.003}

Jones, D.N., \& Figueredo, A.J. (2013). The core of darkness: Uncovering the heart of the Dark Triad. European Journal of Personality, 27, 521-531.

https://doi.org/10.1002/per.1893

Jones, D.N., \& Paulhus, D.L. (2014). Introducing the Short Dark Triad (SD3): A brief measure of dark personality traits. Assessment, 21, 28-41. https://doi.org/10.1177/1073191113514105 
Kahn, J.S. (2009). An introduction to masculinities. Wiley-Blackwell.

Kealy, D., Ogrodniczuk, J.S., Rice, S.M., \& Oliffe, J.L. (2017). Pathological narcissism and maladaptive self-regulatory behaviours in a nationally representative sample of Canadian men. Psychiatry Research, 256, $156-$ 161. https://doi.org/10.1016/j.psychres.2017.06.009

Kiire, S. (2019). A "fast" life history strategy affects intimate partner violence through the Dark Triad and mate retention behavior. Personality and Individual Differences, 140, 46-51.

https://doi.org/10.1016/j.paid.2018.07.016

Konrath, S., Corneille, O., Bushman, B.J., \& Luminet, O. (2014). The relationship between narcissistic exploitativeness, dispositional empathy, and emotion recognition abilities. Journal of Nonverbal Behavior, 38, 129-143. https://doi.org/10.1007/s10919-013-0164-y

Kubarych, T.S., Deary, I.J., \& Austin, E.J. (2004). The Narcissistic Personality Inventory: Factor structure in a non-clinical sample. Personality and Individual Differences, 36(4), 857-872. https://doi.org/10.1016/S01918869(03)00158-2

Kupers, T.A. (2005). Toxic masculinity as a barrier to mental health treatment in prison. Journal of Clinical Psychology, 61(6), 713-724.

\section{https://doi.org/10.1002/jclp.20105}

LeBreton, J.M., Baysinger, M.A., Abbey, A., \& Jacques-Tiura, A.J. (2013). The relative importance of psychopathy-related traits in predicting impersonal sex and hostile masculinity. Personality and individual differences, 55(7), 817-822. https://doi.org/10.1016/j.paid.2013.07.009

Mahmut, M.K., Homewood, J., \& Stevenson, R.J. (2008). The characteristics of non-criminals with high psychopathy traits: Are they similar to criminal psychopaths? Journal of Research in Personality, 42(3), 679-692. https://doi.org/10.1016/j.jrp.2007.09.002

Mankowski, E., \& Maton, K. (2010). A community psychology of men and masculinity: Historical and conceptual review. American Journal of 
Community Psychology, 45, 73-86. https://doi.org/10.1007/s10464-0099288-y

Methot-Jones, T. (2019). Inhuman Targets: Psychopathy, Dehumanization, and

Sexist and Violent Attitudes Towards Women [Brock Unviversity].

Retrived from: http://hdl.handle.net/10464/14584

Miller, J.D., Gentile, B., Carter, N.T., Crowe, M., Hoffman, B.J., \& Campbell, W.K. (2018). A comparison of the nomological networks associated with forced-choice and Likert formats of the Narcissistic Personality Inventory. Journal of Personality Assessment, 100(3), 259-267. https://doi.org/10.1080/00223891.2017.1310731

Miller, J.D., Vize, C., Crowe, M.L., \& Lynam, D.R. (2019). A critical appraisal of the Dark-Triad literature and suggestions for moving forward. Current Directions in Psychological Science, 28(4), 353-360. https://doi.org/10.1177/0963721419838233

Monaghan, C., Bizumic, B., \& Sellbom, M. (2018). Nomological network of twodimensional Machiavellianism. Personality and Individual Differences, 130, 161-173. https://doi.org/10.1016/i.paid.2018.03.047

Muñoz, L.C., Khan, R., \& Cordwell, L. (2011). Sexually coercive tactics used by university students: A clear role for primary psychopathy. Journal of Personality Disorders, 25, 28-40. https://doi.org/10.1521/pedi.2011.25.1.28

Pailing, A., Boon, J., \& Egan, V. (2014). Personality, the Dark Triad and violence. Personality and Individual Differences, 67, 81-86. https://doi.org/10.1016/j.paid.2013.11.018

Parent, M.C., \& Moradi, B. (2011). An abbreviated tool for assessing conformity to masculine norms: Psychometric properties of the Conformity to Masculine Norms Inventory-46. Psychology of Men \& Masculinity, 12, 339-353. https://doi.org/10.1037/a0021904 
Parent, M.C., Gobble, T.D., \& Rochlen, A. (2019). Social media behavior, toxic masculinity, and depression. Psychology of Men \& Masculinities, 20(3), 277-287. https://doi.org/10.1037/men0000156

Paulhus, D.L., \& Williams, K.M. (2002). The Dark Triad of personality: Narcissism, Machiavellianism, and psychopathy. Journal of research in personality, 36(6), 556-563. https://doi.org/10.1016/S0092-6566(02)00505-6

Perkins, S. (2015). Hegemonic masculinity and its effect on attitudes toward seeking professional psychological help. Unpublished PhD thesis. Northeastern University.

Pfabigan, D.M., Seidel, E.-M., Wucherer, A.M., Keckeis, K., Derntl, B., \& Lamm, C. (2015). Affective empathy differs in male violent offenders with highand low-trait psychopathy. Journal of Personality Disorders, 29(1), 42-61. https://doi.org/10.1521/pedi_2014_28_145

Plouffe, R. A., Wilson, C. A., \& Saklofske, D. H. (2020). Examining the Relationships Between Childhood Exposure to Intimate Partner Violence, the Dark Tetrad of Personality, and Violence Perpetration in Adulthood. Journal of Interpersonal Violence, 0886260520948517. https://doi.org/10.1177/0886260520948517

Raskin, R., \& Hall, C.S. (1981). The Narcissistic Personality Inventory: Alternate form reliability and further evidence of construct validity. Journal of Personality Assessment, 45, 159-162.

Tetreault, C., Bates, E. A., \& Bolam, L. T. (2018). How Dark Personalities Perpetrate Partner and General Aggression in Sweden and the United Kingdom. Journal of Interpersonal Violence, 1-25.

https://doi.org/10.1177/0886260518793992

Thacker, L.K. (2019). The danger of 'no': Rejection violence, toxic masculinity and violence against women. ProQuest Dissertations Publishing.

Tran, U.S., Bertl, B., Kossmeier, M., Pietschnig, J., Stieger, S., \& Voracek, M. (2018). "I'll teach you differences": Taxometric analysis of the Dark Triad, trait sadism, and the Dark Core of personality. Personality and Individual 
Differences, 126, 19-24. https://doi.org/10.1016/j.paid.2018.01.015 Valentova, J.V., Moraes Junior, F.P., Štěrbová, Z., Varella, M.A., \& Fisher, M.L. (2019). The association between Dark Triad traits and sociosexuality with mating and parenting efforts: A cross-cultural study. Personality and Individual Differences, 109613. https://doi.org/10.1016/j.paid.2019.109613 Van Doorn, G.H., Dye, J., \& de Gracia, M. (2020). Daddy issues: Friends rather than fathers influence adult men's hegemonic masculinity. Personality and Individual Differences. https://doi.org/10.1016/i.paid.2020.110467

Verschuere, B., van Ghesel Grothe, S., Waldorp, L., Watts, A.L., Lilienfeld, S.O., Edens, J.F., Skeem, J.L., Noordhof, A., Grothe, S. van G., Waldorp, L., Watts, A.L., Lilienfeld, S.O., Edens, J.F., Skeem, J.L., \& Noordhof, A. (2018). What features of psychopathy might be central? A network analysis of the Psychopathy Checklist-Revised (PCL-R) in three large samples. Journal of Abnormal Psychology, 1271), 51-65. https://doi.org/10.1037/abn0000315 Waddell, C., Van Doorn, G., March, E., \& Grieve, R. (2020). Dominance or deceit: The role of the Dark Triad and hegemonic masculinity in emotional manipulation. Personality and Individual Differences, 166, 110160. https://doi.org/10.1016/j.paid.2020.110160

Williams, K., Nathanson, C., \& Paulhus, D. (2003). Structure and validity of the self-report psychopathy scale-III in normal populations. 111th Annual Convention of the American Psychological Association, Toronto, Canada. http://www2.psych.ubc.ca/ dpaulhus/research/DARK_TRIAD/PRESENT ATIONS/APA03_kevin_SRP_poster.pdf 
